\title{
Comparative Analysis of Aerodynamic Characteristics and Experimental Investigation of a Moving Coil Linear Motor Using Computational Fluid Dynamics
}

\author{
Gong ZHANG*, Jimin LIANG*,**, Zhichen HOU*, Qunxu LIN***, Zheng XU*, Jian WANG*, \\ Xiangyu BAO*, Weijun WANG* \\ * Guangzhou Institute of Advanced Technology, Chinese Academy of Science, Guangzhou, 511458 Guangdong, China, \\ E-mail: gong.zhang@giat.ac.cn \\ **Shenzhen Institute of Advanced Technology, Shenzhen, 518055 Guangdong, China, E-mail: jm.liang@giat.ac.cn \\ ***Wuyi University, Jiangmen, 529020 Guangdong, China, E-mail: qx.lin@giat.ac.cn \\ crossref http://dx.doi.org/10.5755/j01.mech.24.6.22463
}

\section{Introduction}

A linear motor (LM), converting the electromagnetic signals into the mechanical signals reciprocating linear motion continuously and proportionally, is looked upon as the most widely employed linear motion mechanism in various industry driving fields. Normally, LM could be divided into 2 types based on the moving part [1-2], that is moving iron LM and moving coil LM. At present, a moving coil linear motor (MCLM) has been drawing widely attention because of high linearity and small hysteresis [35]. Tanaka, etc. [6-7] pointed out the generated electromagnetic force is 1.5 times higher than the others with same size.

Generally, the air damping of the MCLM is usually ignored relative to electromagnetic force [8-9]. However, the air damping has a close association with moving speed and the internal shape of the MCLM [10-11]. Furthermore, along with the raising of the frequency and speed, the effect of air damping on the kinematics characteristics is increasingly remarkably. What's more, in most cases the characteristics are closely related to the properties of the associated components of the system [12-13]. So it is necessary to study aerodynamics of the MCLM and take measures to reduce the air damping. However, as the diversity and complexity of the cavities enclosed by the MCLM, the normal momentum analysis could no longer be able to evaluate the air damping in the process of movement accurately and detailed [14-15]. So the flow fluid simulation method is proposed. In addition, the analysis of the interior flow fluid is necessary to guide the optimum design as well.

To address these shortcomings, in this study, an aerodynamics analysis of an MCLM is conducted using a computational fluid dynamics (CFD) software Fluent to study the air damping characteristics of the electromechanical with different thrust coil bobbins (TCBs) and find a method to reduce.

\section{Analytical model}

A schematic of an MCLM designed in this study is depicted in Fig. 1, the designed MCLM consists of connector, permanent magnet (PM), coil, iron core, end shield, thrust coil bobbin (TCB), output shaft, cover, etc. PMs have been widely used in various applications for many decades to convert electrical energy into mechanical ener- gy. Several PMs are fixed on the inner face of the end shield. The iron core is fixed in the center of the end shield by a screw, and a coil is wrapped on the TCB. The TCB subassembly connected to both a guide pin and the output shaft could keep reciprocating linear motion with high frequency in an airtight cavity enclosed by end shield, cover, PMs, iron core, et al.

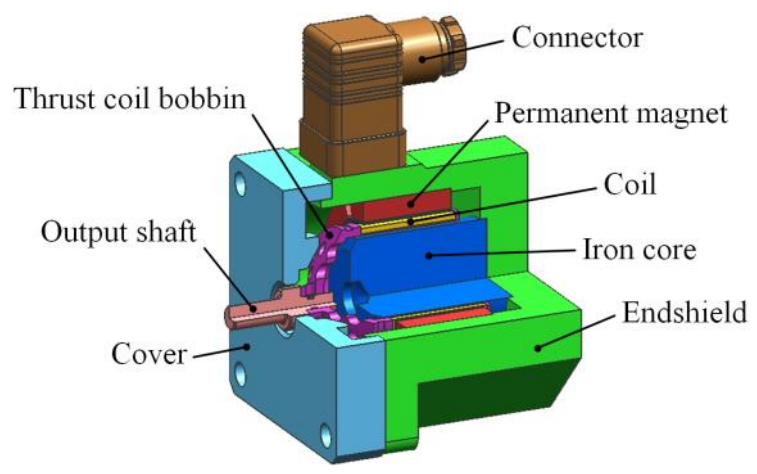

Fig. 1 Schematic of MCLM

A DC voltage signal is applied to the coil through the connector, so that the output shaft together with the TCB connected to the carrying currents coil will realize the reciprocating linear motion due to the effect of the Ampere force of the permanent magnetic field.

To compare the aerodynamic characteristic of the TCB subassembly, a 3D drawing and prototype of three different TCBs with different designs are compared in Figs. 2 and 3.

Proposal 1: the original design with no hole shown in Fig. 2, a and Fig. 3, a.

Proposal 2: new TCB with 8 holes of $\varnothing 4 \mathrm{~mm}$ located the radius of $\varnothing 20 \mathrm{~mm}$ on the end face shown in Fig. 2, b and Fig. 3, b.

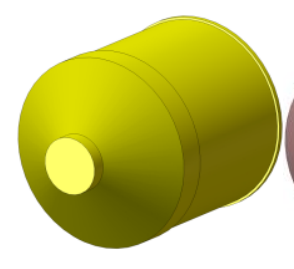

a

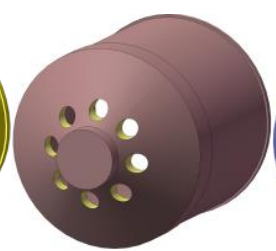

b

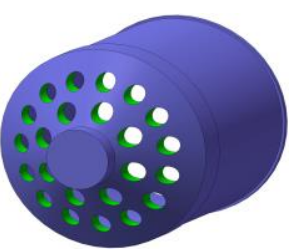

c
Fig. 2 3D drawing of three different TCBs: a -proposal 1, b-proposal 2, c-proposal 3 


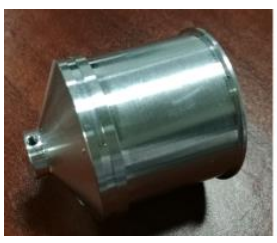

a

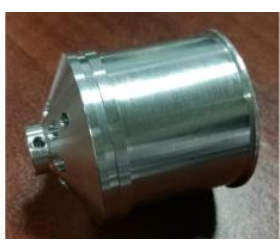

b

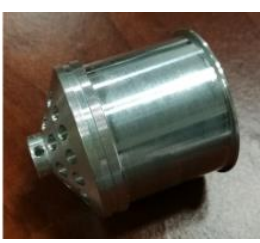

c
Fig. 3 Prototype of three different TCBs: a -proposal 1, bproposal 2, c-proposal 3

Proposal 3: new TCB with 8 holes of $\varnothing 4 \mathrm{~mm}$ located the radius of $\varnothing 20 \mathrm{~mm}$ and 15 holes of $\varnothing 3.5 \mathrm{~mm}$ located the radius of $\varnothing 30 \mathrm{~mm}$ on the end face shown in Fig. 2, c and Fig. 3, c.

$$
\frac{\partial u_{r}}{\partial t}+u_{r} \frac{\partial u_{r}}{\partial r}-\frac{u_{\theta}^{2}}{r}+\frac{u_{\theta}}{r} \frac{\partial u_{r}}{\partial \theta}+u_{y} \frac{\partial u_{r}}{\partial_{y}}=F_{r}-\frac{1}{\rho} \frac{\partial p}{\partial r}+v\left(\frac{\partial^{2} u_{r}}{\partial r^{2}}+\frac{1}{r} \frac{\partial u_{r}}{\partial_{r}}-\frac{u_{r}}{r^{2}}-\frac{2}{r^{2}} \frac{\partial u_{\theta}}{\partial \theta}+\frac{1}{r^{2}} \frac{\partial^{2} u_{r}}{\partial \theta^{2}}+\frac{\partial^{2} u_{r}}{\partial y^{2}}\right) .
$$

When $R / h>>1$, assuming $p=p(r, t), u_{r}=u(r, y, t)$, the unsteady $N-S$ equation can be simplified to: due to the symmetry, Eq. 1 relative to $\theta$ is ignored and thus

$$
\frac{\partial u_{r}}{\partial t}+u_{r} \frac{\partial u_{r}}{\partial r}+u_{y} \frac{\partial u_{r}}{\partial_{y}}=-\frac{1}{\rho} \frac{\partial p}{\partial r}+v\left(\frac{\partial^{2} u_{r}}{\partial r^{2}}+\frac{1}{r} \frac{\partial u_{r}}{\partial_{r}}-\frac{u_{r}}{r^{2}}+\frac{\partial^{2} u_{r}}{\partial y^{2}}\right)
$$

Combining with the mass conservation equation, the pressure distribution on the radial direction can be written as Eq. 3 with the boundary conditions of $u(r, 0, t)=u(r$, $h, t)=0$ and $p(R, t)=p_{0}[17]$.

$$
p=p_{0}+\frac{r^{2}-R^{2}}{2}\left(\frac{6 u \dot{h}}{h^{3}}+\frac{3 \rho \ddot{h}}{5 h}-\frac{15 \rho h^{2}}{14 h^{2}}\right) .
$$

Where: $\dot{h}$ and $\ddot{h}$ are the velocity and acceleration of the plate which is moving towards the lower boundary.

Focus on the mathematical model 1 with only one side closed (depicted in Fig. 4). Integrating Eq. (3) on the area $s$, the air damping of the plate $F_{s}$ can be expressed as.

$$
F_{S}=-\frac{\pi R^{4}}{4}\left(\frac{6 \mu h}{h^{3}}+\frac{3 \rho \ddot{h}}{5 h}-\frac{15 \rho \dot{h}^{2}}{14 h^{2}}\right)
$$

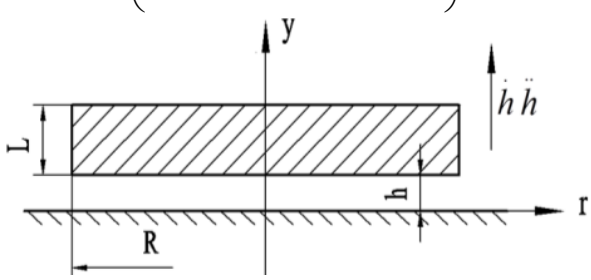

Fig. 4 Mathematical model 1

With regard to mathematical model 2 with all four sides closed (depicted in Fig. 5), similarly, the air damping of the plate $F_{c}$ can be written as [18-19].

$$
F_{C}=-\frac{\pi R^{4}}{4}\left(\frac{6 \mu h}{h^{3}}+\frac{3 \rho \ddot{h}}{5 h}-\frac{15 \rho h^{2}}{14 h^{2}}\right)+\frac{\pi R^{4}}{4}\left(\frac{6 \mu \dot{H}}{H^{3}}+\frac{3 \rho \ddot{H}}{5 H}-\frac{15 \rho H^{2}}{14 H^{2}}\right)-4 \pi R^{2} \mu L B \dot{h} .
$$

Where: $\quad B=\left(R_{1}^{2}-R^{2}\right) R_{1} R /\left\{R_{1} R\left(R_{1}^{2}-R^{2}\right) \times\left[\left(R_{1}^{2}\right.\right.\right.$ $\left.\left.\left.+R^{2}\right) \ln \left(R_{1} / R\right)-R_{1}^{2}+R^{2}\right]\right\}, \dot{H}$ and $\ddot{H}$ are the velocity and acceleration of the plate which is moving towards the upper boundary.

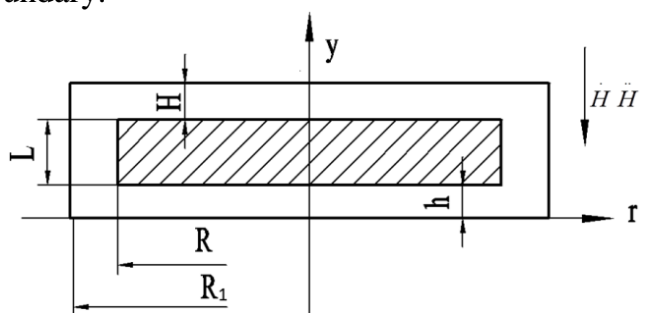

Fig. 5 Mathematical model 2
It is evident from Eq. (5), the air damping is related to not only geometry dimensions of $R, h, H, L, R_{1}$ but also movement parameters of $\dot{h}, \ddot{h}, \dot{H}, \ddot{H}$ and so on.

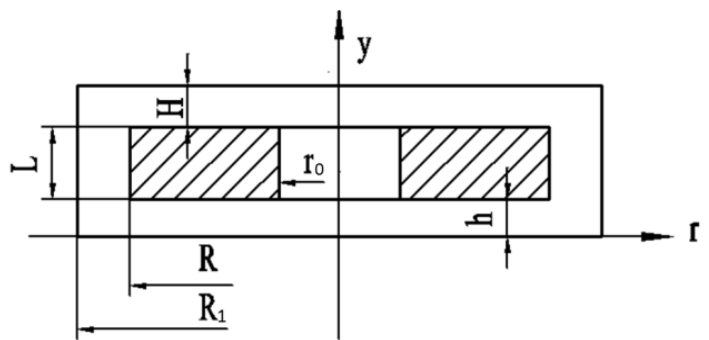

Fig. 6 Mathematical model 3 
Then when it comes to mathematical model 3 with all four sides closed and a hole in the middle of plate (depicted in Fig. 6), it can be predicted that while the plate is moving downwards, the air will be squeezed out through the hole and the gap between the plate and the end shield. Thus a section where the velocity is zero is provided. Using relation $r_{m}=\left(R+r_{0}\right) / 2$, the distribution of pressure can be expressed as:

$$
F_{O}=-\frac{\pi\left(R+\mathrm{r}_{0}\right)\left(R-r_{0}\right)^{3}}{2}\left(\frac{\mu \dot{h}}{h^{3}}+\frac{\rho \ddot{h}}{10 h}-\frac{5 \rho h^{2}}{28 h^{2}}\right)+\frac{\pi\left(R+\mathrm{r}_{0}\right)\left(R-r_{0}\right)^{3}}{2}\left(\frac{\mu \dot{H}}{H^{3}}+\frac{\rho \ddot{H}}{10 H}-\frac{5 \rho H^{2}}{28 H^{2}}\right)-\pi \mu L N \dot{h},
$$

where: $N=\left[\left(R+r_{0}\right)^{2}-4 r_{0}^{2}\right]^{2} / 2 r_{0}^{2}+\left[4 R^{2}-\left(R+r_{0}\right)^{2}\right] B$.

Comparing Eq. (5) and Eq. (7), it is evident that $F_{O}$ is smaller than $F_{C}$. This implies that the air damping of the plate is decreased after holes are punched. In order to evaluate the air damping characteristics intuitively and conduct the simulation below, choosing $R=20 \mathrm{~mm}$; $R_{1}=22 \mathrm{~mm} ; \quad L=10 \mathrm{~mm} ; \quad h=2-0.5 \sin (4000 \times \mathrm{t}) \mathrm{mm}$; $H=2+0.5 \sin (4000 \times t) \mathrm{mm}$. Fig.6 reveals the air damping diagram of model 1 , model 2 and different model 3 . The $r_{0} / R$ is $0.1,0.25,0.5$ for model three (a), model three (b), models three (c) respectively. As evident in Fig. 7, the air damping is smaller while $r_{0} / R$ is increasing.

Though the theoretical analysis above via the MATLAB (MathWorks, Inc.) could reflect the change regulation of the pressure and air damping, it can be just used for the simple models and do some qualitative analysis. As for complex model, the finite element method needs to be used. Thus using CFD software Fluent 14.0 (ANSYS, Inc. USA) for aerodynamics analysis of an MCLM is necessary. In simulation process, the mass conservation equation, the Reynolds equation and the $k-\varepsilon$ turbulent control equation is used [20].

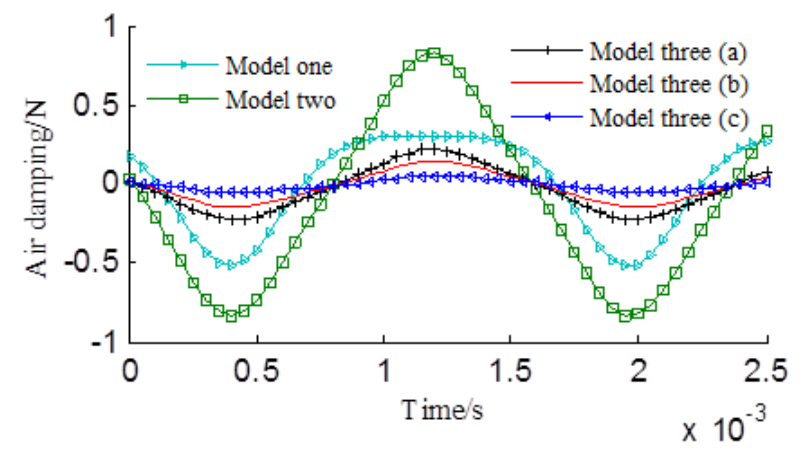

Fig. 7 Air damping curves of three different mathematical models

When the TCB subassembly is moving, the calculation domain is always changing as well. Thus the dynamic meshes technique is required, and unstructured tetrahedral meshes are put in use, which can renew more easily than hexahedral mesh [21]. Fig. 8 presents meshes of the air cavity corresponding to TCB of proposal 1 .

Adopting the methods of spring and remeshing to renew the meshes, and setting the outline of the TCB subassembly to rigid wall and the outer boundary of the air cavity to wall, the movement form of the TCB subassembly is defined by User Defined Function (UDF).

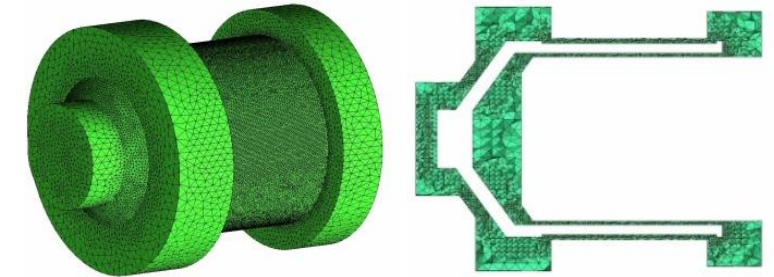

Fig. 8 Meshes of the air cavity corresponding to TCBs of proposal 1

\section{Results and discussion}

The TCB subassembly would be set to move periodically from $-0.5 \mathrm{~mm}$ to $+0.5 \mathrm{~mm}$ according to the sinusoid, the velocity magnitude is $1 \mathrm{~m} / \mathrm{s}, 2 \mathrm{~m} / \mathrm{s}$ and $3 \mathrm{~m} / \mathrm{s}$ respectively, and starts from the middle position. Fig. 9 illustrates the air damping curves of three different proposals at different speed, Fig. 8 is substantial accordant with Fig. 6 as evident. However, there are still some differences between them, as follows.

1. In initial phase, there is a huge deviation. This is mostly because at the beginning of iterating, the calculation in the set time doesn't converge. But over time, along with stability of the flow field, the calculation becomes to converge, which ensures the accuracy of the subsequent data.

2. The curve fluctuates at the peak of the air damping. The reason is that the position of TCB subassembly at this time is at the maximum displacement, and unit of $h$ and $H$ is just millimeter. As can be seen in Eq. 5 and Eq. 7, a small change in the displacement will result in a big impact on the air damping.

3. The upper and lower peak value is different. Definitely, the left and right air cavity of the TCB subassembly is asymmetric.

Fig. 10 details the air damping peaks of three different proposals under different magnitudes of speed. It is evident from the Figure that the air damping of the TCB subassembly increases along with the speed. When the velocity is $3 \mathrm{~m} / \mathrm{s}, 2 \mathrm{~m} / \mathrm{s}$ and $1 \mathrm{~m} / \mathrm{s}$, the peaks of the air damping are $20.3 \mathrm{~N}, 9.01 \mathrm{~N}$ and $2.32 \mathrm{~N}$ respectively, which means the air damping is nearly proportional to the square of the speed. What's more, when it comes to the velocity magnitude of $3 \mathrm{~m} / \mathrm{s}$, the air damping peaks of three different proposals are $20.3 \mathrm{~N}, 7.24 \mathrm{~N}$ and $0.58 \mathrm{~N}$ respectively. Compared with proposal 1, the air damping of proposal 2 and proposal 3 is decreased by $64.3 \%$ and $97.1 \%$ respectively. As seen from the figure that punching on end face of TCB improves obviously aerodynamics. 


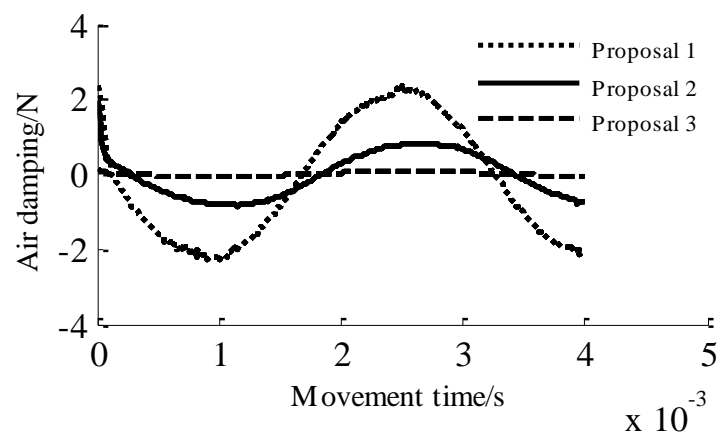

a

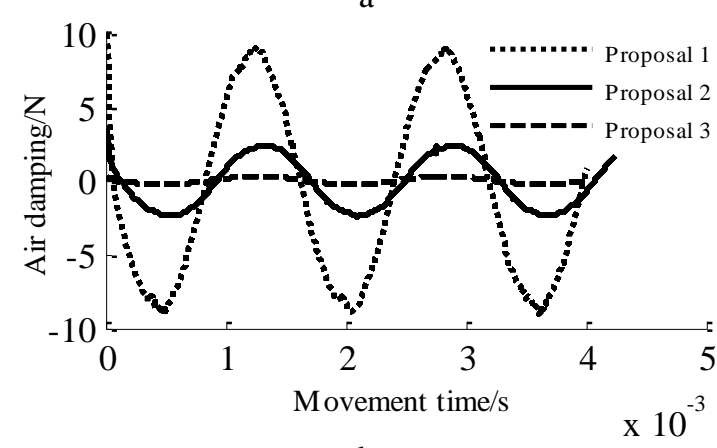

b

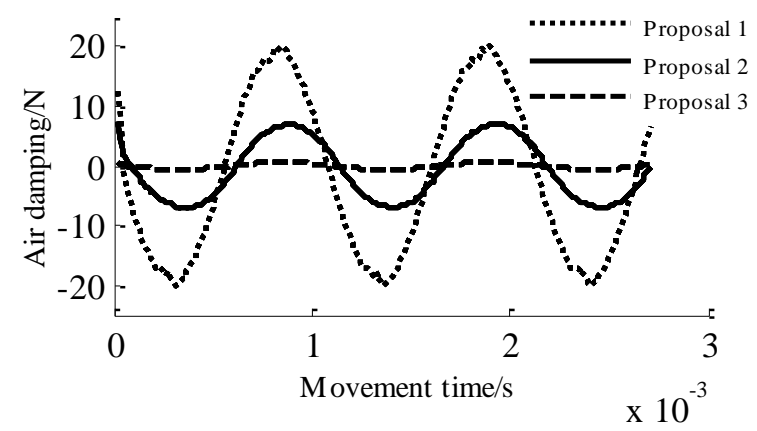

c

Fig. 9 Air damping curves of three different proposals under different magnitudes of speed: a-under $1 \mathrm{~m} / \mathrm{s}, \mathrm{b}$ under $2 \mathrm{~m} / \mathrm{s}$, c-under $3 \mathrm{~m} / \mathrm{s}$

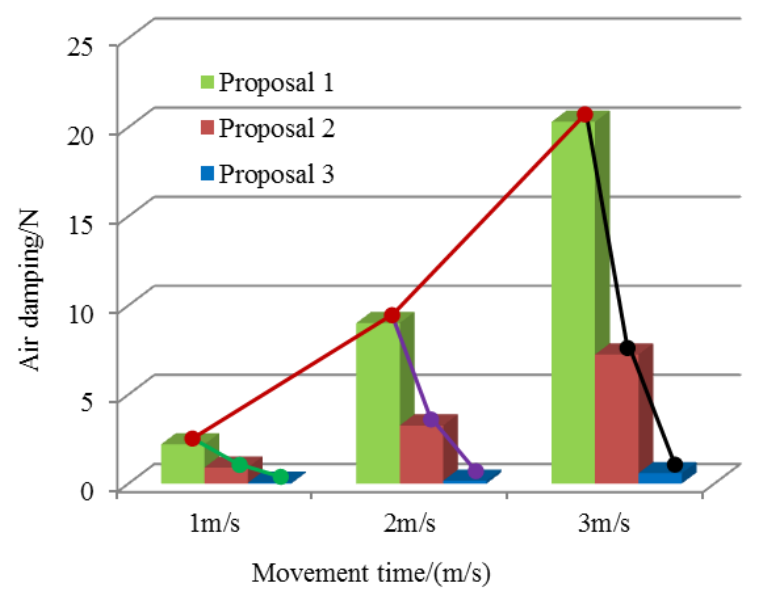

Fig. 10 Air damping peaks of three different proposals under different magnitudes of speed

For a better understanding of simulation results, a detailed analysis of the flow field is required. Because the beginning of flow filed is unstable, so four positions started from the $1 / 4$ phase are chosen. When the movement time is $0.5 \mathrm{~T}$, the TCB subassembly is moving toward the left and provided with a maximum velocity. Pressure con- tour diagrams and velocity vector diagrams of three different proposals at the time of $0.5 \mathrm{~T}$ with the speed of $3 \mathrm{~m} / \mathrm{s}$ are shown in Fig. 11 and Fig. 12 respectively.

As seen in Fig. 11, the pressure difference between left and right cavity in proposal 2 and 3 are greatly reduced compared with proposal 1 . Especially in proposal 3 , the left and right cavity's pressure is almost equal, so the air damping is smaller. As detailed in Fig. 12, as for proposal 1, the air flow rate in the narrow channel between TCB subassembly and end shield is very high. There is eddy current at the import and export of the flow channels. However, with regard to proposal three, not only the fluid velocity but also the eddy current region and intension are definitely reduced.

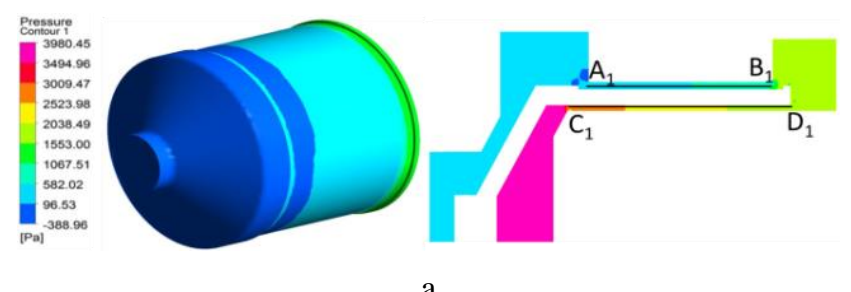

a

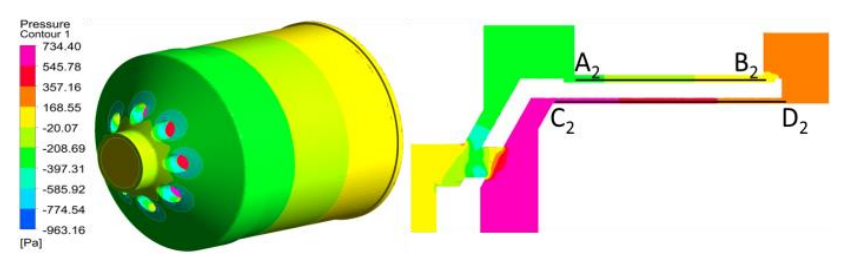

b

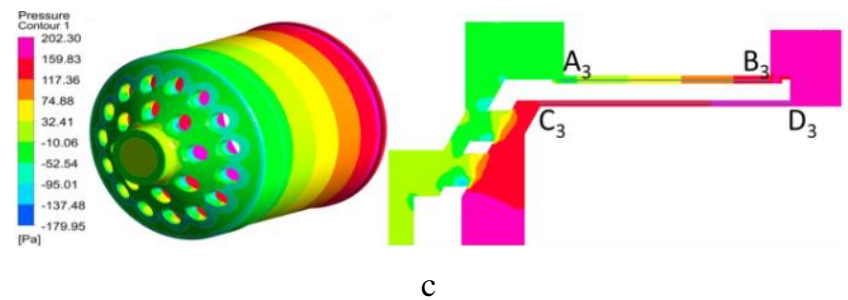

Fig. 11 Pressure contour diagrams of three different proposals under the time of $0.5 \mathrm{~T}(3 \mathrm{~m} / \mathrm{s})$ : a -proposal $1, \mathrm{~b}$-proposal 2, c-proposal 3

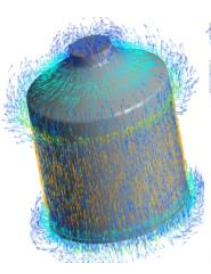

a
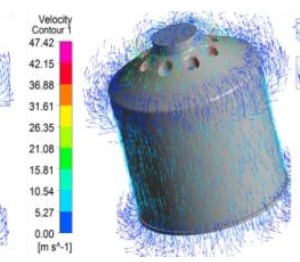

b

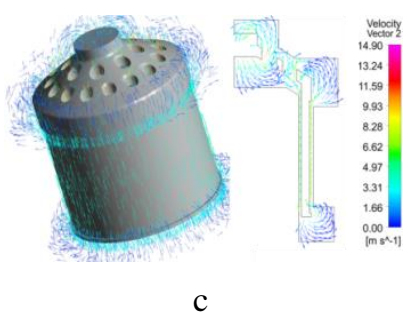

Fig. 12 Velocity vector diagrams of three different proposals under the time of $0.5 \mathrm{~T}(3 \mathrm{~m} / \mathrm{s})$ : a -proposal $1, \mathrm{~b}$-proposal 2, c-proposal 3

Fig. 13 lists the pressure and velocity of three different proposals, the maximum pressure of proposal 1 is 
3908.5Pa, while proposal 3 is only $202.5 \mathrm{~Pa}$, which reduces by $94.9 \%$. In addition, the maximum velocity is reduced from $47.4 \mathrm{~m} / \mathrm{s}$ to $14.9 \mathrm{~m} / \mathrm{s}$ by $68.6 \%$.

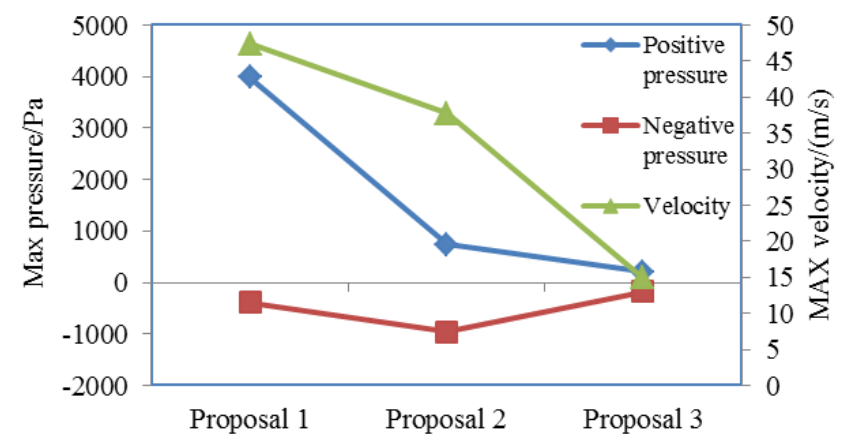

Fig. 13 Max pressure and velocity of three different proposals at the speed of $0.5 \mathrm{~T}(3 \mathrm{~m} / \mathrm{s})$

As for the narrow up-channel $\mathrm{AB}$ and downchannel CD of three proposals exhibited in Fig. 11, their pressure curves are illustrated in Fig. 14 and Fig. 15. It can be seen from the figure that two channels of proposal 1 are provided with a higher pressure and pressure gradient. This is because the channel is narrow so that eddy current occurs at the import and export, the pressure curve experiences a larger change at point B nearby. As regards proposal three, the pressure is obviously reduced and is not high at point $\mathrm{C}$ while low at point $\mathrm{D}$ any more, the pressure gradient is reversed, high pressure areas appear near the tail of the cavity where contributes little to the air damping.

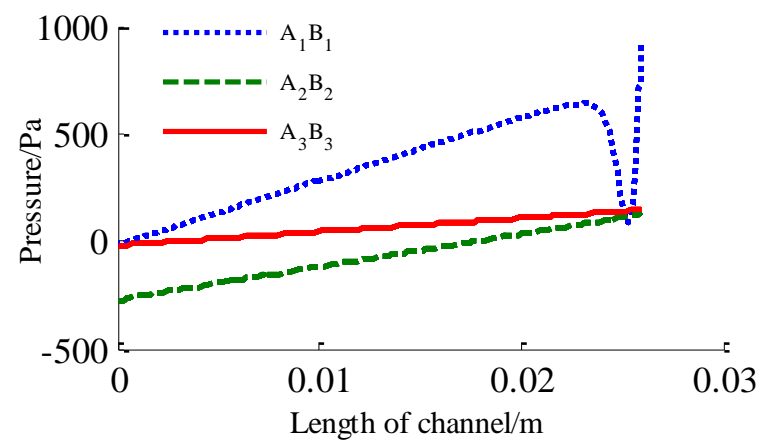

Fig. 14 Pressure curves of channel $\mathrm{AB}$ of different proposals

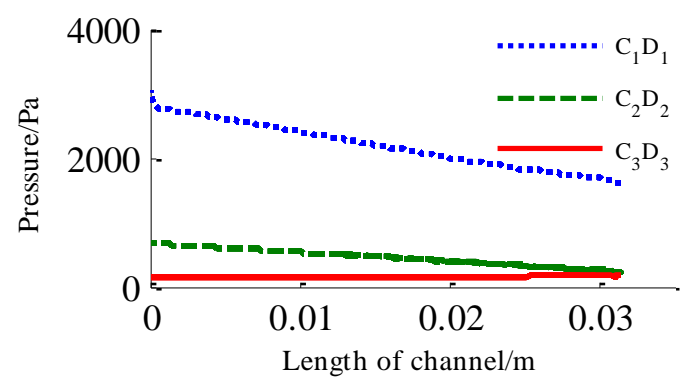

Fig. 15 Pressure curves of channel CD of different proposals

Combined with the streamline diagrams depicted in Fig.16, air flowing from right cavity to left cavity needs to pass the long narrow channel and can't arrive at the left cavity timely, then results in air blocking phenomenon. While in proposal three, almost all of the air flowing from right to left cavity gets across the punched holes. As a re- sult, the air flow stress in the narrow channel is relieved and air damping is decrease as well.

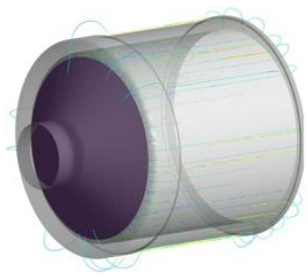

a
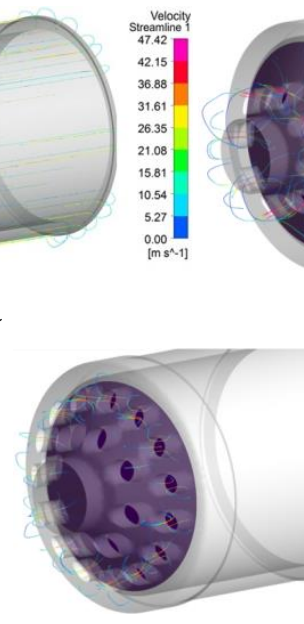

C

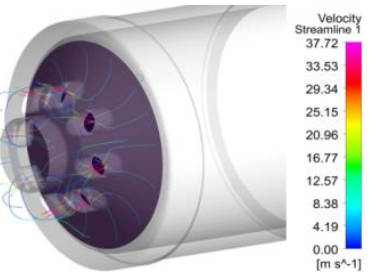

b
Fig. 16 Streamline diagrams of different proposals $(3 \mathrm{~m} / \mathrm{s})$ : a -proposal 1, b-proposal 2, c-proposal 3

Using software MATLAB 9.1 (MathWorks, Inc. USA) for control analysis, curves of step response and frequency response of three different proposals are compared in Fig. 17 and Fig. 18, respectively. Dynamic performance characteristics of three different proposals are listed in Table 1. As evident in figure and table, the dynamic performance index of proposal 3 is better than proposal 1 and proposal 2 , the response time and frequency of the proposal 3 arrives at $2.3 \mathrm{~ms}, 386 \mathrm{~Hz} /-3 \mathrm{~dB}, 440 \mathrm{~Hz} /-90^{\circ}$, respectively. Simulation results show that the dynamic performance of proposal 3 is improved after punching a number of holes on the end face of the TCB.

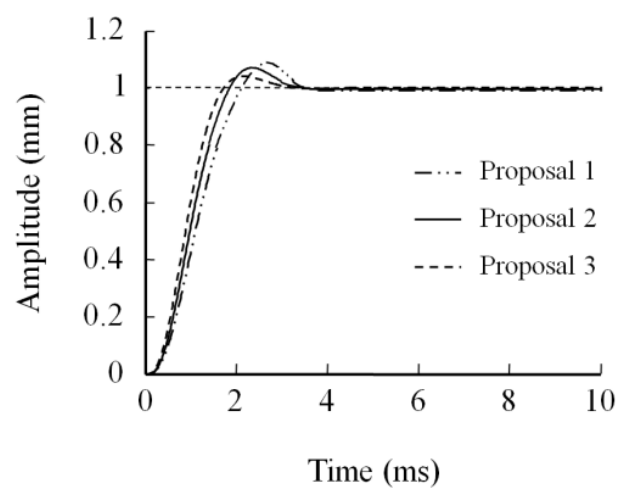

Fig. 17 Step response curves of three different proposals

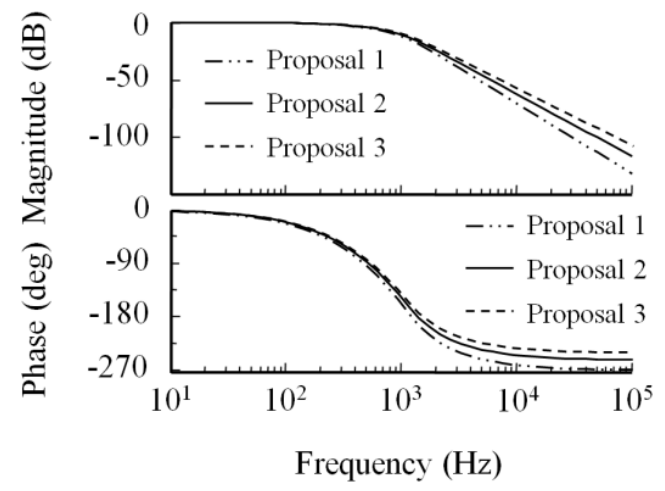

Fig. 18 Frequency response curves of three different proposals 
Table 1 with different input signal frequency provided by the sig-

Dynamic performance characteristics of three different proposals

\begin{tabular}{|c|c|c|c|c|}
\hline \multicolumn{2}{|c|}{ Category } & Proposal & Pro- & Proposal \\
\hline \multirow{2}{*}{$\begin{array}{c}\text { Step } \\
\text { response }\end{array}$} & $\begin{array}{c}\text { Adjusting } \\
\text { time }(\mathrm{ms})\end{array}$ & 3.2 & 2.7 & 2.3 \\
\hline & Overshoot & $8.7 \%$ & $7.3 \%$ & $4.1 \%$ \\
\hline \multirow{2}{*}{$\begin{array}{c}\text { Frequency } \\
\text { response }\end{array}$} & $\begin{array}{c}\text { Gain(Hz/- } \\
3 \mathrm{~dB})\end{array}$ & 362 & 375 & 386 \\
\hline & $\begin{array}{c}\text { Phase(Hz/- } \\
\left.90^{\circ}\right)\end{array}$ & 408 & 427 & 440 \\
\hline
\end{tabular}

\section{Experimental procedures}

Experimental analyses had been carried out at a designed MCLM with proposal 3 under actual testing conditions. A digital controller collects the desired position signal and position feedback signal generated by the position sensor on the output shaft. After comparison and compilation, the controller provides a drive current to different coils via a connector, so that the designed MCLM can keep the reciprocating linear motion.

Fig. 19 reveals an image of the prototype of the designed MCLM. A signal generator provides ten groups sinusoidal AC voltage with amplitude of $5 \mathrm{~V}$ and frequency from $1 \mathrm{~Hz}$ to $320 \mathrm{~Hz}$ to the coils of TCB, respectively. Both the input signals provided by the signal generator, and the feedback signal generated by the displacement sensor on the output shaft are collected to an oscilloscope, as detailed in Fig. 20.
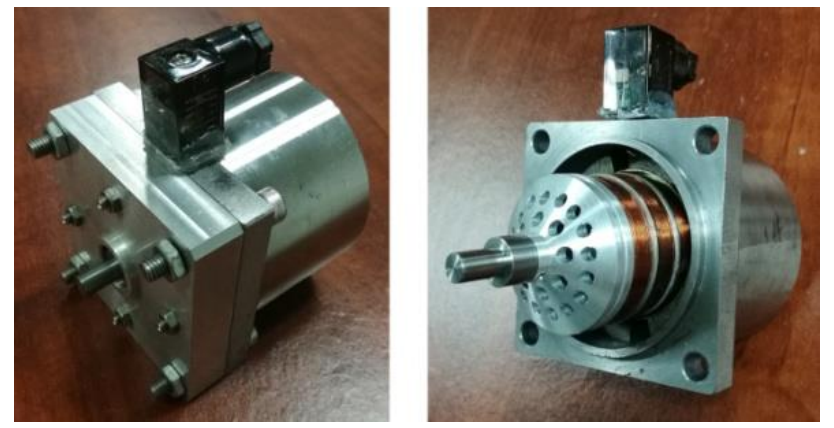

Fig. 19 Prototype of the designed MCLM

As we can see from figure, when the input signal frequency is $1 \mathrm{~Hz}$, the output voltage amplitude would be $1.26 \mathrm{~V}$. In this case, there is a good linear relationship between input and output, and the phase difference between them is close to 0 (Fig. 20, a). While the input signal frequency is $150 \mathrm{~Hz}$, the output voltage amplitude would be $1.08 \mathrm{~V}$. Likewise, there is also a good linear relationship between input and output, and the phase difference between them is small as well (Fig. 20, b).

While the input signal frequency is $260 \mathrm{~Hz}$, the output voltage amplitude would be $0.938 \mathrm{~V}$. There is a good linear relationship between input and output similarly. However, the phase difference between them is larger than before (Fig. 20, c). While the input signal frequency is $320 \mathrm{~Hz}$, at this point, phase difference between input and output is over 90 degrees. However, they still keep a good linear relationship (Fig. 20, d).

Table 2 exhibits the output voltage amplitude provided by the displacement sensor on the output shaft nal generator.

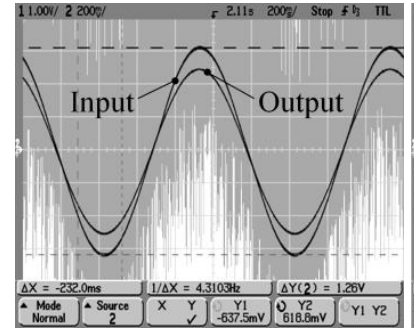

a

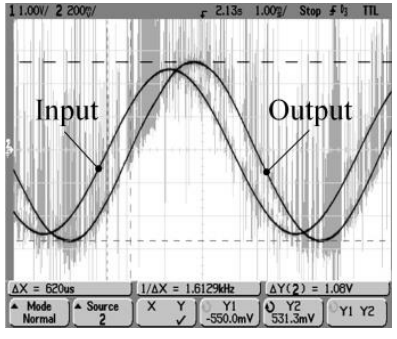

b

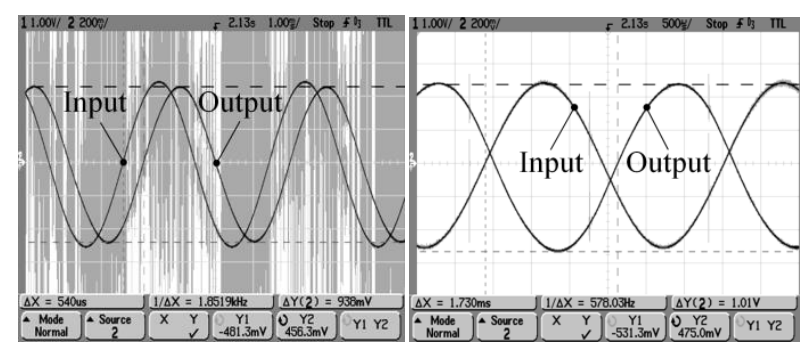

c

d

Fig. 20 Tracking characteristics of sinusoidal signal between input and output of the designed MCLM: a- under $1 \mathrm{~Hz}, \mathrm{~b}$-under $150 \mathrm{~Hz}, \mathrm{c}-$ under $260 \mathrm{~Hz}$, d-under $320 \mathrm{~Hz}$

Table 2

The output voltage amplitude with different input signal frequency

\begin{tabular}{|c|c|c|c|c|c|}
\hline $\begin{array}{c}\text { Input signal } \\
\text { frequency (Hz) }\end{array}$ & 1 & 7 & 20 & 30 & 100 \\
\hline $\begin{array}{c}\text { Output voltage } \\
\text { amplitude (V) }\end{array}$ & 1.26 & 1.24 & 1.24 & 1.21 & 1.17 \\
\hline $\begin{array}{c}\text { Input signal } \\
\text { frequency (Hz) }\end{array}$ & 150 & 200 & 260 & 300 & 320 \\
\hline $\begin{array}{c}\text { Output voltage } \\
\text { amplitude (V) }\end{array}$ & 1.08 & 1.03 & 0.938 & 0.919 & 1.01 \\
\hline
\end{tabular}

According to the tracking characteristics of sinusoidal signal based on the output shaft of the designed MCLM, a curve of the experimental magnitude-frequency characteristics of the designed MCLM is presented Fig. 21. As evident in figure, the experimental frequency of the designed MCLM arrives at $300 \mathrm{~Hz}$ at $3 \mathrm{~dB}$.

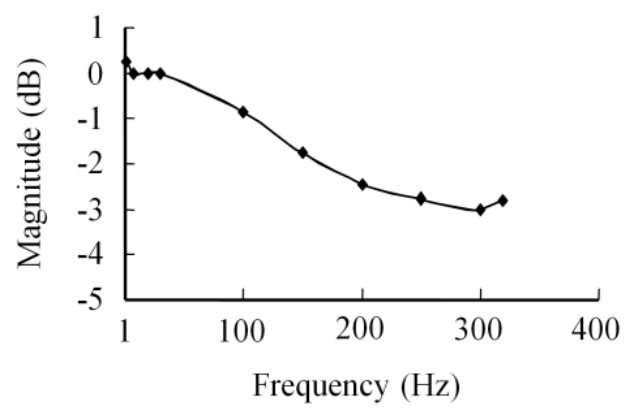

Fig. 21 Curve of the experimental magnitude-frequency characteristics of the designed MCLM

In addition, after a square wave signal with amplitude of $5 \mathrm{~V}$ and frequency of $25 \mathrm{~Hz}$ provided by the signal generator is loaded into the coils of bobbins, the feedback signal generated by the displacement sensor on the output shaft are collected to an oscilloscope, as detailed in Fig. 22. 
As evident in figure, the experimental response time of the designed MCLM is close to $4 \mathrm{~ms}$.

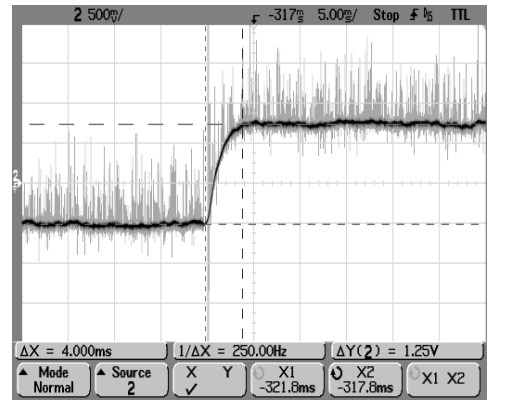

Fig. 22 Picture of feedback square wave signal based on the output shaft of the designed MCLM

Furthermore, after a triangle wave signal with amplitude of $2.5 \mathrm{~V}$ and frequency of $12.5 \mathrm{~Hz}$ provided by the signal generator is loaded into the coils of bobbins, the feedback signal generated by the displacement sensor on the output shaft are collected to an oscilloscope, as detailed in Fig. 23. As detailed in figure, under this situation, there is a good linear relationship between input and output, and the phase difference between them is close to $80 \mathrm{~ms}$.

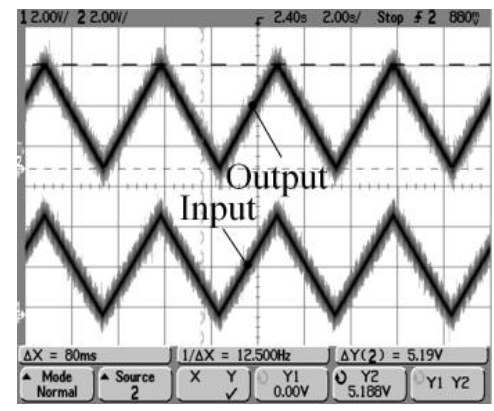

Fig. 23 Tracking characteristics of triangle wave signal between input and output of the designed MCLM

Experimental procedures show promising results that the designed MCLM displays high frequency and rapid response, and the designed control technology can realize high performance.

\section{Conclusions}

A three-dimension aerodynamics analysis and experimental investigation of the designed MCLM provided with different TCBs based on dynamic meshes technique using CFD software are proposed in this study. Conclusions are as follows:

The air damping loaded to moving TCB subassembly is nearly proportional to the square of the speed, which is provided with a significant influence on the kinematics characteristics of the MCLM working at conditions of high-frequency and high-speed.

Punching a number of holes on the end face of the TCB could greatly enhance the air flow capacity and improve the distribution of pressure and velocity of the flow field around. Compared with proposal 1, the air damping of proposal 2 and proposal 3 is decreased by $64.3 \%$ and $97.1 \%$, respectively. Results show the effectiveness of the proposed optimization of the TCB is verified.

The simulation response time and frequency of the designed MCLM with proposal 3 arrives at $2.3 \mathrm{~ms}$,
$386 \mathrm{~Hz} /-3 \mathrm{~dB}, 440 \mathrm{~Hz} /-90^{\circ}$, respectively. Simulation results show that the dynamic performance index of the designed MCLM with proposal 3 is better than those with proposal 1 and proposal 2 . In addition, the experimental frequency and response time of the designed MCLM with proposal 3 are $300 \mathrm{~Hz}$ at $3 \mathrm{~dB}$ and $4 \mathrm{~ms}$, respectively.

As evident in this study, analysis and experimental results show that the air damping can be decreased by the structural optimization of the MCLM at the high speed working conditions, and the designed MCLM with proposal 3 can realize good performance of high frequency and rapid response.

\section{Acknowledgments}

This research is supported by the National Natural Science Foundation of China (Grant No. 51307170), the Guangzhou Scientific Planning Programs of China (Grant No. 201607010041), and the Shenzhen Basic Research Projects of China (Grant No. JCYJ20160531184135405). The authors gratefully acknowledge the help of Guangzhou Institute of Advanced Technology, Chinese Academy of Sciences and Shenzhen Institute of Advanced Technology.

\section{References}

1. Takezawa, M.; Kikuchi, H.; Suezawa, K. et al. 1998. High frequency carrier type bridge-connected magnetic field sensor, IEEE Transactions on Magnetics 34(4): 1321-1323. https://doi.org/ 10.1109 / INTMAG.1998.742576.

2. Goll, D.; Kronmuller, H. 2000. High-performance permanent magnets, Naturwissenschaften 87(10): 423438. https://doi.org/10.1007/s001140050755.

3. Zhao, S.; Tan, K. K. 2005. Adaptive feedforward compensation of force ripples in linear motors, Control Engineering Practice 13: 1081-1092. https://doi.org /10.1016/j.conengprac.2004.11.004.

4. George, A.; William, T. 2000. Performance evaluation of a permanent magnet brushless DC linear drive for high speed machining using finite element analysis, Finite Elements in Analysis and Design 35: 169-188. https://doi.org/10.1016/S0168-874X(99)00064-5.

5. Ruan, X. F. 2013. Simulation model and experimental verification of electro-hydraulic servo valve, Applied Mechanics and Materials 328: 473-479.

https://doi.org/10.4028/www.scientific.net/AMM.328.4 73.

6. Zhang G.; Yu, L Y.; Ke, J. 2007. High frequency moving coil electromechanical converter, Electric Machines and Control 11(3): 298-302. https://doi.org/10.1002/jrs.1570.

7. Sadre, M. 1997. Electromechanical converters associated to wind turbines and their control, Solar Energy 6(2): 119-125. https://doi.org/10.1016/S0038-092X(97)00034-0.

8. Amirante, R.; Catalano, L A.; Tamburrano, Paolo. 2014. The importance of a full 3D fluid dynamic analysis to evaluate the flow forces in a hydraulic directional proportional valve, Engineering Computations 31(5): 898-922.

https://doi.org/10.1108/EC-09-2012-0221.

9. Sorli, M.; Figliolini, G.; Pastorelli, S. 2004. Dynamic 
model and experimental investigation of a pneumatic proportional pressure valve, Mechatronics, IEEE/ASME Transactions on 9(1): 78-86. https://doi.org/10.1109/TMECH.2004.823880.

10. Amirante, R.; Moscatelli, P G.; Catalano, L A. 2007. Evaluation of the flow forces on a direct (single stage) proportional valve by means of a computational fluid dynamic analysis, Energy Conversion \& Management 48: 942- 953. https://doi.org/10.1016/j.enconman.2006.08.024.

11. John, A. Fundamentals of aerodynamics, McGraw Hill Higher Education, New York, 2010. https://doi.org/10.1001/jama.1943.02840050078041.

12. Ryashentsev, N. P.; Kovalev, Y. Z.; Fedorov, V. K. et al. 1978. A mathematical model of an electromechanical converter, Mechanization and Automation in Mining, (4): 47-55. https://doi.org/10.1007/BF02499577.

13. Ismagilov, F. R.; Khairullin, I. H.; Riyanov, L N. et al. 2013. A mathematical model of a three-axis electromechanical converter of oscillatory energy. Russian Electrical Engineering 84(9): 528-532. https://doi.org/10.3103/S106837121309006X.

14. Huang, L. H.; Xu, Y. L.; Liao, H. L. 2014. Nonlinear aerodynamic forces on thin flat plate: Numerical study, Journal of Fluids and Structures 44: 182-194. https://doi.org/10.1016/j.jfluidstructs.2013.10.009.

15. Miguel, M. P.; Gonzalo, L. P.; Jiménez, L. et al. 2013. CFD model of air movement in ventilated façade: comparison between natural and forced air flow, International Journal of Energy \& Environment 4(3): 357-368.

http://www.ijee.ieefoundation.org/vol4/issue3/IJEE_01 _v4n3.pdf.

16. John, A. Fundamentals of aerodynamics. McGraw Hill Higher Education, New York, 2010. https://doi.org/10.1001/jama.1943.02840050078041.

17. Kuzma, D. C. 1967. Fluid intertia effects in squeeze films, Appl. Sci. Res 18: 16-20. https://doi.org/10.1007/bf00382330.

18. Huang, S. J.; Andra, D.; Tasciuc, B. et al. 2011. A simple expression for fluid inertia force acting on micro-plates undergoing squeeze film damping, Proceedings: Mathematical, Physical and Engineering Sciences 467(2126) : 522-536. https://doi.org/10.1098/rspa.2010.0216.

19. Joseph, Y. J. 1998. Squeeze-film damping for MEMS structures, Massachusetts Institute of Technology.

20. Lomax, H.; Pulliam, T. H.; David, W. Z. 2001. Fundamentals of computational fluid dynamics. Springer Verlag, https://doi.org/10.1007/978-3-662-04654-8.

21. Smolarkiewicz, P. K.; Szmelter, J.; Wyszogrodzki, A. A. 2013. An unstructured-mesh atmospheric model for nonhydrostatic dynamics, Journal of Computational Physics 254: 184-199. https://doi.org/10.1016/j.jcp.2013.07.027.

G. Zhang, J. Liang, Zh. Hou, Q. Lin, Zh. Xu, J. Wang, S. Liang, W. Wang

\section{COMPARATIVE ANALYSIS OF AERODYNAMIC CHARACTERISTICS AND EXPERIMENTAL INVESTIGATION OF A MOVING COIL LINEAR MOTOR USING COMPUTATIONAL FLUID DYNAMICS}

S u m m a r y

This study tries to observe the aerodynamics of a moving coil linear motor (MCLM) under the conditions of high frequency and high speed, a three-dimension aerodynamics analysis and experimental investigation of the designed MCLM provided with different thrust coil bobbins (TCBs) based on dynamic meshes technique using computational fluid dynamics (CFD) are proposed. Results show that with the increase of moving frequency and speed, the air damping of TCB subassembly is nearly proportional to the square of the speed. Punching a number of holes on the end face of the TCB could greatly improve the air flow capacity and enhance the distribution of pressure and velocity of the flow field around. Compared with proposal 1, the air damping of proposal 2 and proposal 3 is decreased by $64.3 \%$ and $97.1 \%$, respectively. Simulation results show that the response time and frequency of the designed MCLM with proposal 3 is better than those with proposal 1 and proposal 2. In addition, the experimental frequency and response time of the designed MCLM with proposal 3 are $300 \mathrm{~Hz}$ at $3 \mathrm{~dB}$ and $4 \mathrm{~ms}$, respectively. As evident in this study, analysis and experimental results show that the air damping can be decreased by the structural optimization of the MCLM, and the designed MCLM with proposal 3 can realize good performance of high frequency and rapid response.

Keywords: moving coil linear motor; thrust coil bobbin; aerodynamics; dynamic mesh; experimental investigation.

Received May 07, 2018

Accepted December 12, 2018 